\title{
Response to letter to editor about the article: comparison of the safety and efficacy of one-shot and telescopic metal dilatation in percutaneous nephrolithotomy: a randomized controlled trial
}

\author{
Shahriar Amirhassani - Seyed Habibollah Mousavi-Bahar • \\ Abdolmajid Iloon Kashkouli · Saadat Torabian
}

Received: 12 May 2014 / Accepted: 4 June 2014 / Published online: 4 July 2014

(c) Springer-Verlag Berlin Heidelberg 2014

\section{Dear Editor;}

We appreciate Tevfik Ziypak, M.D., Senol Adanur, M.D. and Turgut Yapanoglu, M.D. [1] in order to write the letter regarding our article [2]. Although we agree with their precious points of view regarding the different parts of our study and this is very obvious that their team is familiar to PCNL, we have addressed their concerns as possible as follow. Sample size was estimated by an expert in medical research designing, based on the majority of similar previous study including our references [3-5]. Although fluoroscopy time was basic comparison factor in current study, other parameters such as success rate and Hemoglobin drop could be influenced in different dilatation techniques and may be decreased value of each of techniques. Although majority of fluoroscopy time belongs to the access creation and the tract dilatation, separate measurement of radiation time in each phase can be more informative, and is better to be measured in next studies. Comprehensive data about stone burden already have been explained in the text and tables (Staghorn or complex stones of $>2.5 \mathrm{~cm}$ diameter were seen in $31(62 \%)$ and $33(66 \%)$ of group A and B patients, respectively $(P=0.41))$.

Conflict of interest The authors declare that they have no conflict of interest.

\section{References}

1. Tevfik Ziypak, MD, Senol Adanur, MD, Turgut Yapanoglu MD. Ataturk University, Medical Faculty, Department of Urology, Erzurum, Turkey

2. Amirhassani S, Mousavi-Bahar SH, Iloon Kashkouli A, Torabian S (2014) Comparison of the safety and efficacy of one-shot and telescopic metal dilatation in percutaneous nephrolithotomy: a randomized controlled trial. Urolithiasis

3. Amjadi M, Zolfaghari A, Elahian A, Tavoosi A (2008) Percutaneous nephrolithotomy in patients with previous open nephrolithotomy: one shot versus telescopic technique for tract dilatation. J Endourol 22(3):423-425

4. Ziaee MSA, Karami K, Aminsharifi A, Mehrabi S, Zand S, Javaherforooshzadeh A (2007) One-stage tract dilation for percutaneous nephrolithotomy: is it justified? J Endourol 21(12):1415-1420

5. Frattini A, Barbieri A, Salsi P, Sebastio N, Ferretti S et al (2001) One shot: a novel method to dilate the nephrostomy access for percutaneous lithotripsy. J Endourol 15(9):919-923
S. Amirhassani · S. H. Mousavi-Bahar · A. Iloon Kashkouli ( $\square)$.

S. Torabian

Urology and Nephrology Research Center, Hamadan University

of Medical Sciences, Hamadan, Iran

e-mail: ilounmajid@yahoo.com 